\title{
Building Information Modeling (BIM) Utilization for 3D Fiscal Cadastre
}

\author{
Sadikin Hendriatiningsih, Andri Hernandi, Asep Yusup Saptari, Ratri Widyastuti and Dhendy Saragih \\ Institut Teknologi Bandung, Bandung, Indonesia
}

Received: 2018-03-16 Accepted: 2019-10-16

\section{Keywords: \\ BIM; TLS;}

building tax

Correspondent Email: ratri@gd.itb.ac.id

\begin{abstract}
Parcels data in Indonesia are still stored in 2-dimensional (2D) geometry which are integrated with other attribute data, such as the case with the Directorate of Land and Building Tax Indonesia. Whereas, building taxes assessment refers to a number of details that require the information to be stored in 3-dimensional (3D) forms. This study aims at the use of Building Information Modeling (BIM) technology, which widely used in building asset management in 3D. This research illustrates the usability of the role of BIM in assessing and managing building taxes in Indonesia. The point clouds were obtained using Terrestrial Laser Scanner (TLS) technology. The point clouds processed so that it can form 3-dimensional geometrical apartment. The attributes of the 3-dimensional model integrated with the geometric model using the BIM concept. The results analyzed to assess whether BIM concept was able to fulfill the needs of the 3D fiscal cadastre in Indonesia.
\end{abstract}

C 2019 by the authors. This article is an open access article distributed under the terms and conditions of the Creative Commons Attribution(CC BY NC) licensehttps://creativecommons.org/licenses/by-nc/4.0

\section{Introduction}

A cadastre is complete inventory registration of land parcels in any state or jurisdiction that contain information about parcels ownership, valuation, location, area, land use, and any buildings or any structure above (Williamson, 2013). Nowadays, researches are developing the 3-dimensional cadastre which can be interpreted as cadastral system that registers and gives description of rights and limitations (restriction), not only on land parcels, but also on land on the 3D property unit (Stoter, 2004). 3D cadastre has not been used and developed in Indonesia. Parcel data storage in Indonesia is still stored in 2-dimensional geometry that is integrated with other attribute data, as in the case of the Indonesian Directorate of Land and Building Tax. Tax data collection is done by using a Tax Object Notification Letter (SPOP) which is filled by the property owner or survey officer. SPOP must be filled according to actual conditions. If the SPOP is not filled correctly, then the building tax calculation cannot be calculated correctly and the building owner gets an administrative fine. Data filled in SPOP are the type of building, building area, year of built, year of renovation, condition of building, construction of buildings, roofs, walls, ceilings, facilities such as air conditioning, swimming pool, tennis court, and type of fence. To overcome these problems, a technology that is able to collect land and building tax data accurately and whose data can be stored and accessed in 3-dimensional form is needed.

Currently, the use of Building Information Modeling (BIM) technology is widely used in building assets management. BIM is a technology that is capable display 3-dimensional models of buildings and information in them (Mordue et al., 2016). Additionally, BIM is a tool that can accelerate growth and increase competitiveness in the construction sector. Information provided by BIM is useful for decision making, planning and treatment of assets. BIM also provides a structured framework for the creation, collection and exchange of information about assets (EUBIM, 2017).

There are various kinds of data acquisition techniques for making 3-dimensional models with BIM, scanning, photogrammetry, virtual modelling, 3D printing and rapid prototyping to capture information about existing buildings and environments (Laing et al., 2014). The research suggests that best data acquisition technique using scanning technology that can be done for larger scale spatial data in high speed would produce highly detailed point clouds which can be used in BIM processing. Therefore, this research used scanning technology such as Terrestrial Laser Scanning (TLS) device to collect the data.

Laser (Light Amplification by Stimulated Emission of Radiation) is defined as a technology capable of generating visible light waves using only a very small spectrum bandwidth. Laser emits visible light with a very narrow sweep area and low divergence. This causes the wavelength produced by visible light to be shorter so that the energy produced is greater. Because of its ability, the laser is then used for various purposes, one of which is in the field of measurement. Laser measurement is known as laser scanning using a Laser Scanner or Terrestrial Laser Scanner (TLS) (Quentiro et al., 2008). 


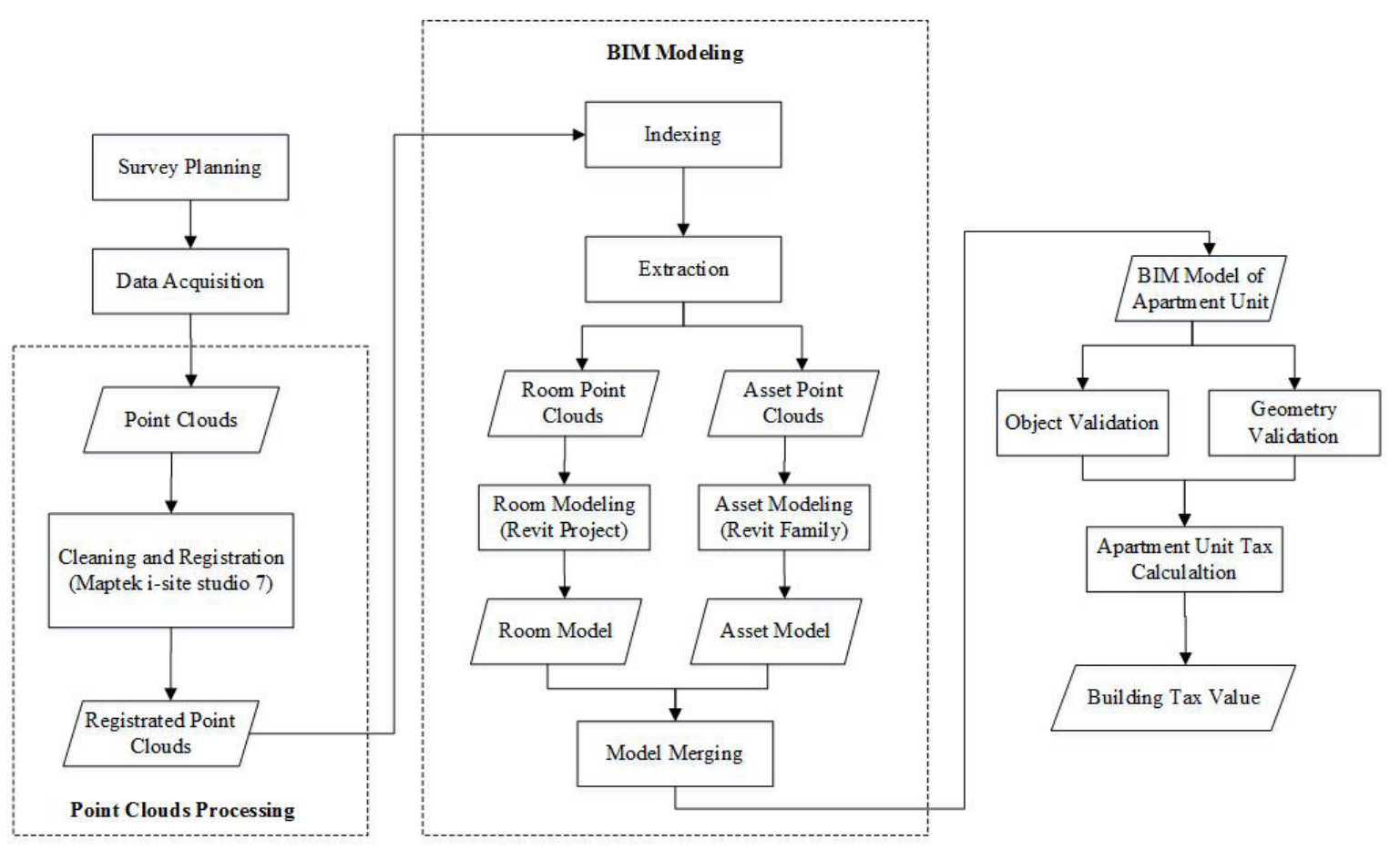

Figure 1. Research Methodology

BIM utilization is increasing over time in many countries. North America is the fastest growth of BIM utilization that is increasing from $28 \%$ in 2007 to $49 \%$ in 2009 and $71 \%$ in 2012. India is the lowest growth of BIM utilization. The cumulative of BIM utilization among countries all over the world is $48.53 \%$ (Shaikh et al., 2016). However, the use of BIM is still limited in architecture, engineering, and construction industry (Kerosuo et al., 2015). Currently, no one has used BIM for building tax assessment, so that purpose of this research is to know how far the role of BIM in assessing and managing building taxes in Indonesia.

\section{The Methods}

The methodology of this research can be shown in Figure 1.

\section{Integration BIM and 3D Fiscal Cadastre Concept 3D Fiscal Cadastre}

Cadastre can be defined as a land information system that is managed by one or more government institutions (International Federation Surveyors, 1995). Cadastre is a parcels-based land information system that contains information about interests in land (eg rights, boundaries, and responsibilities) along with geometric descriptions of parcels relating to the nature of interests, parcels value, parcel ownership, and enhancements. This can be used for fiscal purposes (e.g. fair assessment and taxation), legal purposes (transportation), to assist in land management and land use (e.g. for planning and other administrative purposes), and to enable sustainable development and environmental protection. Stoter (2004) defines
3D cadastre as a cadastre that registers and provides insight into rights and restrictions not only on parcels but on 3D property units (Stoter, 2004). Based on the definitions of FIG and Stoter, 3D fiscal cadastre can be concluded to be a land information system that is usually managed by one or more governments that contain rights and restrictions for fiscal purposes (e.g. fair assessment and taxation), not only on parcels but on $3 \mathrm{D}$ property units.

A fiscal cadastre requires the description, the boundaries definition, ownership, and the land value (Maurer \& Paugam, 2000). It is important to make a complete inventory of all properties and assign a unique property identification number for each parcel to enable tracking of all parcels. Property identifiers also make it possible to link valuations, billing, and property transfer records (Bird \& Slack, 2002).

\section{Building Information Modeling (BIM)}

Building Information Modeling (BIM) is a digital representation in the building in the form of physical and functional characteristics that can be used as a source of knowledge about facilities in the building that are used for decision making from the beginning onwards (NBIS, 2015). BIM can be classified based on its purpose, for example to be utilized to gather building information; to produce building information; to analyze and examine building elements and their feasibility; to design or exchange information on building elements; to make, control and develop building elements (Kreider \& Messner, 2013). There are four main steps in BIM. The first step is identifying BIM values for planning, design, construction, and 
operations; second, is making a BIM system for the processing stage; third, is the exchange of information from all elements in BIM; fourth, is a quality control procedure that supports the implementation of BIM (Kreider \& Messner, 2013). There are fundamental differences between Computer Aided Design (CAD) and BIM which are often considered the same by most people. In $\mathrm{CAD}$, the data are not mutually integrated so it cannot form a system that is stored in the same place, whereas in BIM, CAD is used to form BIM and the data are integrated so that data will be connected and stored in the same place (Demchak et al., 2009).

\section{Terrestrial Laser Scanner (TLS)}

The working principle of Terrestrial Laser Scanner is a time-based measurement where the scanner records two events in the same time frame. In general, time-based measurements can be classified into two, namely measurements based on phase difference (phase difference based) and pulse-based (pulse based) (Quentiro et al., 2008). The principle of positioning using TLS is using data angles and distance results to target. Distance can be obtained based on calculations using time-of-flight, while the angle is obtained from the measurement using Angle Measuring System (AMS) tools in TLS. AMS determines changes and movements of tools horizontally and vertically, so that angles used as an azimuth to determine the position of the point against TLS with the polar method (Reshetyuk, 2009). Figure 2 illustrate how TLS works

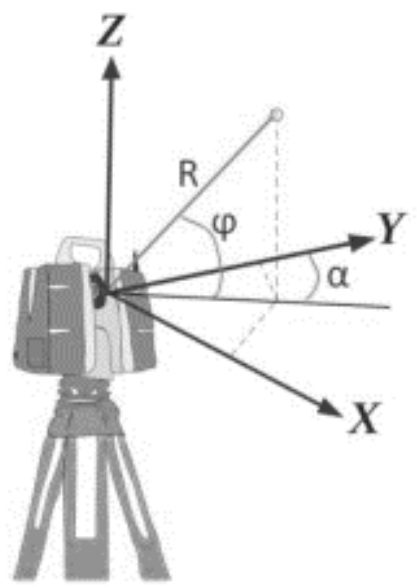

Figure 2. Illustration of TLS works (Setiawan, 2016)

TLS can record thousands and even millions of points with one scan, a collection of points known as point clouds. The recorded point has a certain density level called spatial resolution. Spatial resolution shows the ability of the TLS gauge in recording. The higher the spatial resolution, the more closely the scan results to represent the actual object. Likewise, the lower the spatial resolution, the sparser the scan results are (Reshetyuk, 2009).

\section{Building Tax Calculation}

In this research, the building tax calculation was only carried out on residential building units because shared land and shared buildings were not included in the research object. The approach to valuing residential buildings used is Replacement New Cost (RCN) which is an estimate of the cost of development by using material prices and wages at the time of the valuation date as a replacement building with the same usability, size, design but material that may be different. Minister of Public Works and Human Settlements of Indonesia and data on the prices of building materials in Bandung City in 2017 as referenced to calculate the price of building component in this research.

There are several steps to calculate the building tax (Syahfitriane, 2018):

a. Determine the type of work based on unit data of development work. Each type of work is equipped with material composition and coefficients

b. Determine the cost of each type of work based on the volume of work.

c. Determine the cost of procuring residential building facilities.

d. Calculate RCN value

e. Calculate depreciation using the Straight Line Method

The equation as follow:

Depreciation Value $(\mathrm{Rp})=\mathrm{JBDD} \times \mathrm{RCN}$

Where:

JBBD : Number of Months from Built to Rated

UEB : Economic Age in the Month

RCN : Replacement Cost New, in rupiah.

f. Calculate the final building value

The equation as follow:

Final building value $(\mathrm{Rp})=\mathrm{RCN}-$ Depreciation Value

g. Calculate the building tax by multiplying the final building value used $0.1 \%$ of building tax rate

\section{Data Acquisition}

Data acquisition for this study is an apartmentlike object, a dormitory building in Institut Teknologi Bandung Campus. The process of acquiring a license to measure apartment objects requires a long time, so dormitory building was selected to represent apartment object because of its similarity. Data acquisition begins with conducting a reconnaissance survey to determine the availability of control points in the field. Based on the results of the preliminary survey, it is known that the available control points are quite far from the research location, so that new control points must be constructed first. The method of making control points was done by measurements using GNSS RTK (Real Time Kinematics) and Electronic Total Station (ETS). Figure 3 shows control point measurement using GNSS RTK and ETS. 


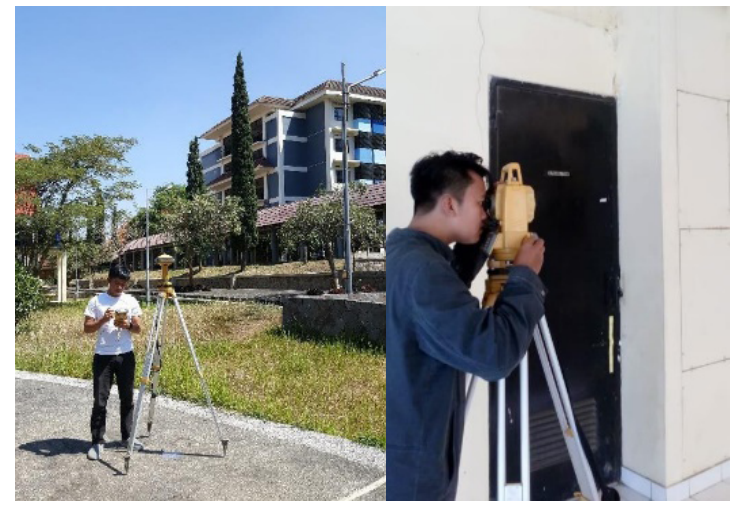

Figure 3. Control point measurements

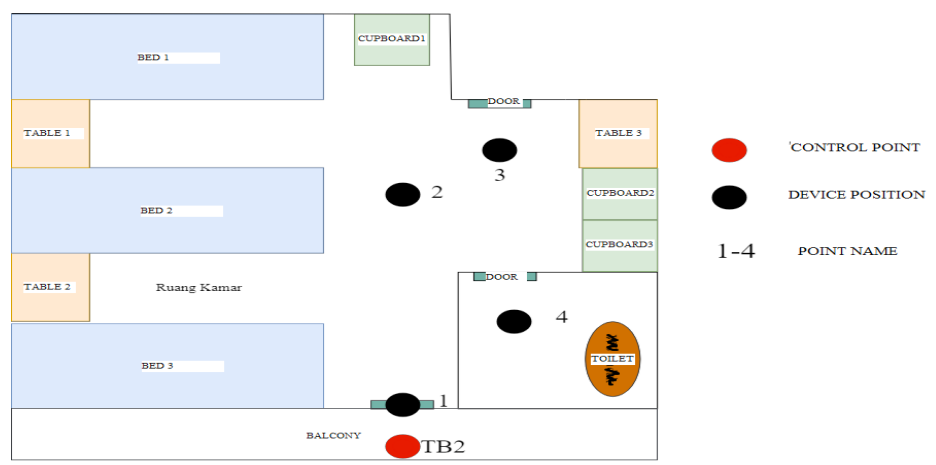

Figure 4. Sketch of indoor TLS measurements

The possible way to collect the point clouds data inside and outside of apartment building is by using non-metric camera device or Terrestrial Laser Scanner (TLS) device. However, this research was using TLS device because TLS is the best device to provide better accuracy to produce 3D models (Barus et al., 2017). The TLS type was Topcon GLS-2000 Terrestrial Laser Scanner series which has ability of Full Dome Fieldof-View (FOV) $360^{\circ}$ (Horizontal) and $270^{\circ}$ (Vertical), can measure the height accurately and automatically, and has time-ability of-flight which is capable of producing clear signals so that it can detect objects well. Moreover, to help the data processing, the height of the device had to be measured first. The height of the device was obtained using measuring tape. The sketch of indoor TLS measurement can be seen in Figure 4 . The figure shows the control point and device position distribution. There were three device position inside the room. Different device positions have benefit avoiding the blind spot of objects inside the room. There are four types of scanning resolution, namely very high $(3.1 \mathrm{~mm}$ at $10 \mathrm{~m}$ distance $)$, high $(6.3 \mathrm{~mm}$ at $10 \mathrm{~m}$ distance $)$, medium $(12.5 \mathrm{~mm}$ at $10 \mathrm{~m}$ distance $)$ and low $(25 \mathrm{~mm}$ at $10 \mathrm{~m}$ distance) resolutions. The selected scanning resolution of measurement is $12.5 \mathrm{~mm}$ because this scanning resolution is the efficient way to collect and process the point clouds data. The objects that were needed to be scanned in this research were less than 50 $\mathrm{mm}$ (based on the wall and window thickness). So that, the scanning resolution had to be smaller but using 3.1 $\mathrm{mm}$ and $6.3 \mathrm{~mm}$ cause the data acquisition stage and the data processing stage takes longer rather than using $12.5 \mathrm{~mm}$ or $25 \mathrm{~mm}$ scanning resolution. The smaller of the scanning resolution, the result would be better.

This field measurement produces 'point clouds' inside and outside room in dormitory building in Institut Teknologi Bandung Campus.

\section{'Point Clouds' Processing}

This stage aims to produce a full $3 \mathrm{D}$ visualization of the room by carrying out the point cloud data registration method from the TLS Topcon GLS-2000 scanner. 'Point clouds' processing is carried out using Maptek i-Site Studio 7.0 software. The scan results from Topcon GLS-2000 are then referred to as raw data. The software cannot directly use raw data for processing. Therefore, conversion of raw data is done before to a format that can be read, .e57 format. Data format conversion was done using Magnet Collage software. That conversion doesn't change the measurement data and can be used for the next processing. The field measurement data still contains noise, which is data that are not needed in processing so it must be discarded. In this research, the noise is point clouds that are not the room objects such as trees or other buildings that were also recorded when taking the data. The process for removing noise from data is called cleaning or filtering. 
Cleaning is done by selecting point clouds that are not the intended object using the Select vertex tool on Maptek software then deleting it with the delete button. Cleaning is done one by one on the scan data from each observation station. Data cleaning was done manually to produce good quality of geometrical object.

After cleaning the noise, next step is registration process which is a technique of combining several results of scanning so that a complete model of the observed object is formed. In this study the type of registration is indirect registration using the cloudto-cloud registration technique by utilizing overlays of two minimum scan results of $30 \%-40 \%$ to be able to complete six orientation parameters, three rotation parameters and three translation parameters. This technique was applied to the Maptek software in two stages, the manual transformation and the global registration. Manual transformation is the first step to bring together two different scanning results. The difference in orientation is because the coordinates of point clouds are bound to the local TLS coordinate system, so that when there is a transfer of the observation station, the TLS coordinate system will experience a change of orientation. The thing to do at this stage is to choose one scan result that is used as a reference, then the two scan results are united and have the same orientation.

The next stage is global registration using the Iterative Closest Point (ICP) algorithm. The user will manually choose at least three corresponding points.
The selected three corresponding points are different from the other scan result. The ICP algorithm will check the iterative distance between point clouds and estimate changes to combine the two scan results to produce a minimum error. Figure 5 shows 'point clouds' processing of outside and inside room with 12.5 $\mathrm{mm}$ density.

\section{Building Information Modeling (BIM) Processing}

Point clouds of the registration results are used as a framework to make BIM room object. The software used is Autodesk Revit 2016 software (student version). This software was used to develop room and asset model from 'point clouds' processing result. The room modeling development is consisting of making the floor, wall and roof of the room using the data point clouds of the room. At this stage the component specifications are made. Detailed descriptions of components specification were needed such as type of constituent material, component dimensions, component structure, color, and etc. Meanwhile, assets modeling development is the process of making room building units such as windows, doors, tables, chairs, water closets, and mattresses. Developing the window, door and water closet model, uses the template provided by software and to develop tables, mattresses, and chairs was done by manually drawing from 'point clouds'. Figure 6 shows room modeling of dormitory building. Figure 7 shows cupboard as asset modeling of dormitory building.
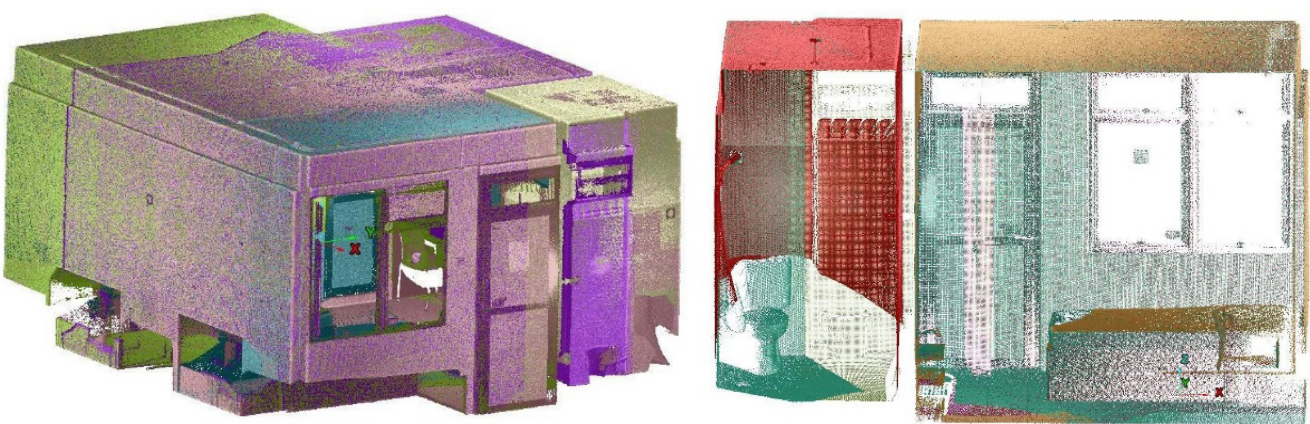

Figure 5. 'Point clouds' processing of outside and inside room with $12.5 \mathrm{~mm}$ density

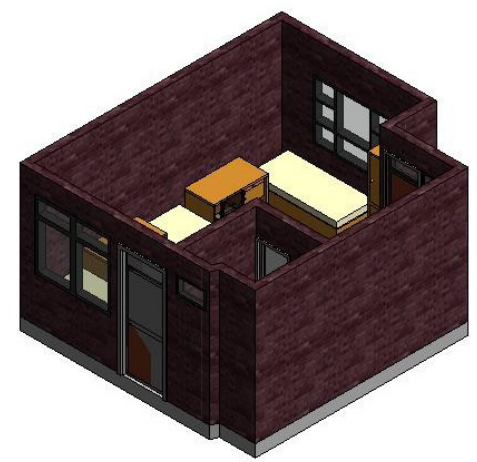

Figure 6. Room modeling of dormitory building 


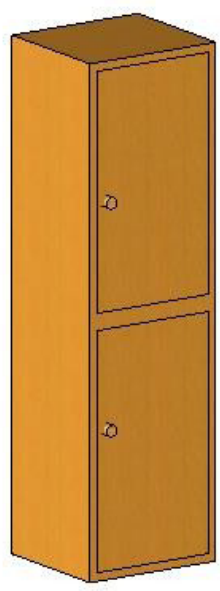

Figure 7. Cupboard object as asset modeling of dormitory building

\begin{tabular}{|c|c|c|c|}
\hline \multicolumn{4}{|c|}{$<$ Dinding $>$} \\
\hline A & B & C & D \\
\hline Family & Structural Material & Area & Volume \\
\hline Basic Wall & Brick, Common & $3 \mathrm{~m}^{2}$ & $0.40 \mathrm{~m}^{3}$ \\
\hline Basic Wall & Brick, Common & $2 \mathrm{~m}^{2}$ & $0.32 \mathrm{~m}^{3}$ \\
\hline Basic Wall & Brick, Common & $11 \mathrm{~m}^{2}$ & $1.69 \mathrm{~m}^{3}$ \\
\hline Basic Wall & Brick, Common & $2 \mathrm{~m}^{2}$ & $0.22 \mathrm{~m}^{3}$ \\
\hline Basic Wall & Brick, Common & $1 \mathrm{~m}^{2}$ & $0.13 \mathrm{~m}^{3}$ \\
\hline Basic Wall & Brick, Common & $6 \mathrm{~m}^{2}$ & $0.87 \mathrm{~m}^{3}$ \\
\hline Basic Wall & Brick, Common & $14 \mathrm{~m}^{2}$ & $2.09 \mathrm{~m}^{3}$ \\
\hline Basic Wall & Brick, Common & $6 \mathrm{~m}^{2}$ & $0.86 \mathrm{~m}^{3}$ \\
\hline Basic Wall & Brick, Common & $3 \mathrm{~m}^{2}$ & $0.42 \mathrm{~m}^{3}$ \\
\hline Basic Wall & Brick, Common & $4 \mathrm{~m}^{2}$ & $0.60 \mathrm{~m}^{3}$ \\
\hline
\end{tabular}

Figure 8. An example displayed of wall information of unit apartment

Autodesk Revit software can display 3D models and information of building. BIM information is displayed in the form of a database on software. Then the type of information is displayed according to the needs. By using an additional program from the software, the database can be exported and imported in other format, so that it can be read and/or modified in other software such as Microsoft Excel, Microsoft Access, MySQL, etc. Figure 8 shows an example how the building information is displayed.

\section{Apartment Unit Tax Calculation}

The approach to valuing residential buildings is using Replacement New Cost (RCN) as mentioned from the sub-section 2.1.3. BIM information can be used to calculate type of work based on the material as known from the BIM information. The cost of each type of work can be determined based on the volume of work which can be known from the building area produced by BIM. The cost of procuring residential building facilities is also known from BIM information. Table 1 is a simulation to assess the building tax based on the sub-section 2.1.3.
Table 1. Apartment Unit Tax Value Calculation

\begin{tabular}{cc}
\hline Works Explanation & Total Cost \\
\hline Roof component & Rp 4,286,655 \\
Wall component & Rp 23,179,259 \\
Floor component & Rp 20,975,121 \\
Facility component & Rp 7,937,959 \\
Total & Rp 56,378,994 \\
Depreciation & Rp 18,041,278 \\
Building Value & Rp 38,337,715 \\
Apartment Unit Tax & Rp 38,337 \\
\hline
\end{tabular}

Apartment Unit Tax is part of the building tax calculation in the form of an apartment. Therefore, this simulation of apartment unit tax calculation can be used to calculate the building tax of apartment. 


\section{Result and Discussion}

The results of the data processing provided the $3 \mathrm{D}$ objects geometric information that was integrated with the non-spatial data information. The needs of building tax calculation is based on material volume and objects information. Therefore, the accuracy of object volume, completeness of the object must be assessed.

\section{Accuracy of Object Geometry}

The 3D object geometric should fulfil the need of tax building calculation. Referring to the sub-chapter 2.5, the apartment unit tax calculation consists of four components. The geometric result, as can be seen in Figure 6 and 7, show that the wall, floor, roof, and facilities component could be saved in the geometric database and be visualized into 3D form. The basic point clouds shown in Figure 5, could be the basic form to build 3D object apartment inside and outside the room. Visually, the result of the integration of point clouds inside and outside of the room is able to provide good visualization (figure 4). However, it needs to be studied more deeply, particularly related to the accuracy of its position. The Root Mean Square Error (RMSE) value is the average distance between the sampling distances between the samples used during registration, and the smaller the RMSE value the better the registration results. The average RMSE value from the registration results using $12.5 \mathrm{~mm}$ is $0.001 \mathrm{~m}$.

Asset Modeling need to study the geometrical quality. The geometry quality of TLS measurements is determined by comparing the dimensions of objects in point clouds to the dimensions of objects in actual conditions. Comparative data were obtained using an iron measuring tape with $0.5 \mathrm{~mm}$ precision. Table 2 shows the result of geometry quality of objects inside room.

The RMSE of geometric object is $0.001 \mathrm{~m}$ based on the RMSE calculation of the deviation between the volume of objects of the processing result and the volume of object from the tape measurement.

Table 2. Object geometry deviation

\begin{tabular}{cc}
\hline Objects & Deviation $(\mathrm{m})$ \\
\hline Window wide & -0.001 \\
Bathroom wall thick & 0.001 \\
Cupboard wide & 0.001 \\
Cupboard height & 0.002 \\
Bed wide & -0.001 \\
\hline
\end{tabular}

Table 3. TLS usability to provide tax objects information

\begin{tabular}{ccc}
\hline Requirement taxation object & $\begin{array}{c}\text { Data Provided from } \\
\text { TLS }\end{array}$ & $\begin{array}{c}\text { Data Provided from } \\
\text { secondary survey }\end{array}$ \\
\hline Building area & Yes & No \\
Numbers of floors & Yes & Yes \\
Apartment construction & No & Yes \\
Roof material & No & Yes \\
Wall material & No & Yes \\
Floor material & No & Yes \\
Ceiling material & No & Yes \\
Numbers of Air Conditioning & Yes & Yes \\
\hline
\end{tabular}

Source of taxation object: Appendix of Tax Object Notification Letter (LSPOP)

Directorate General of Taxation of Indonesia 


\section{Objects Information}

Data recording using TLS could provide detailed point clouds to be processed into 3D model of apartment unit including its facilities, but the material information could not be provided from the TLS scanning process. It can be obtained by secondary data acquisition where the researcher took notes of the object's material information. Table 3 shows how the requirements of building information from data acquisition processed.

Based on Table 3, TLS scanning only provided the area and numbers of objects, but others information is not provided. Therefore, other building information were obtained from other methods of data acquisition.

\section{Apartment Unit Database}

Revit Software is database structure to manage $3 \mathrm{D}$ engineering building. It simplifies the $3 \mathrm{D}$ object building process but does not provide tax entities to calculate the building tax. Therefore, the database structure on Revit software needs to be modified. Figure 9 shows the modification of database structure.

The default entities on Revit software are walls as 'Walls', floors as 'Floors', ceilings as 'Ceilings', doors as 'Doors', and windows as 'Windows' that are connected to the default database structure. These five entities are the required components to calculate the unit tax. The modification was done by adding two entities such as 'Unit' and 'Price_List'. 'Unit' entity contains the description that are related to the unit tax on apartment building. 'Price_List' entity contains the description that are related to the price list of objects in apartment unit. Every object entity such as floors, windows, ceilings, windows, and doors have a unique ID connected to the unit entity and price list entity. Figure 10 shows the contents of the price list entity and Figure 11 shows the contents of the unit entity.

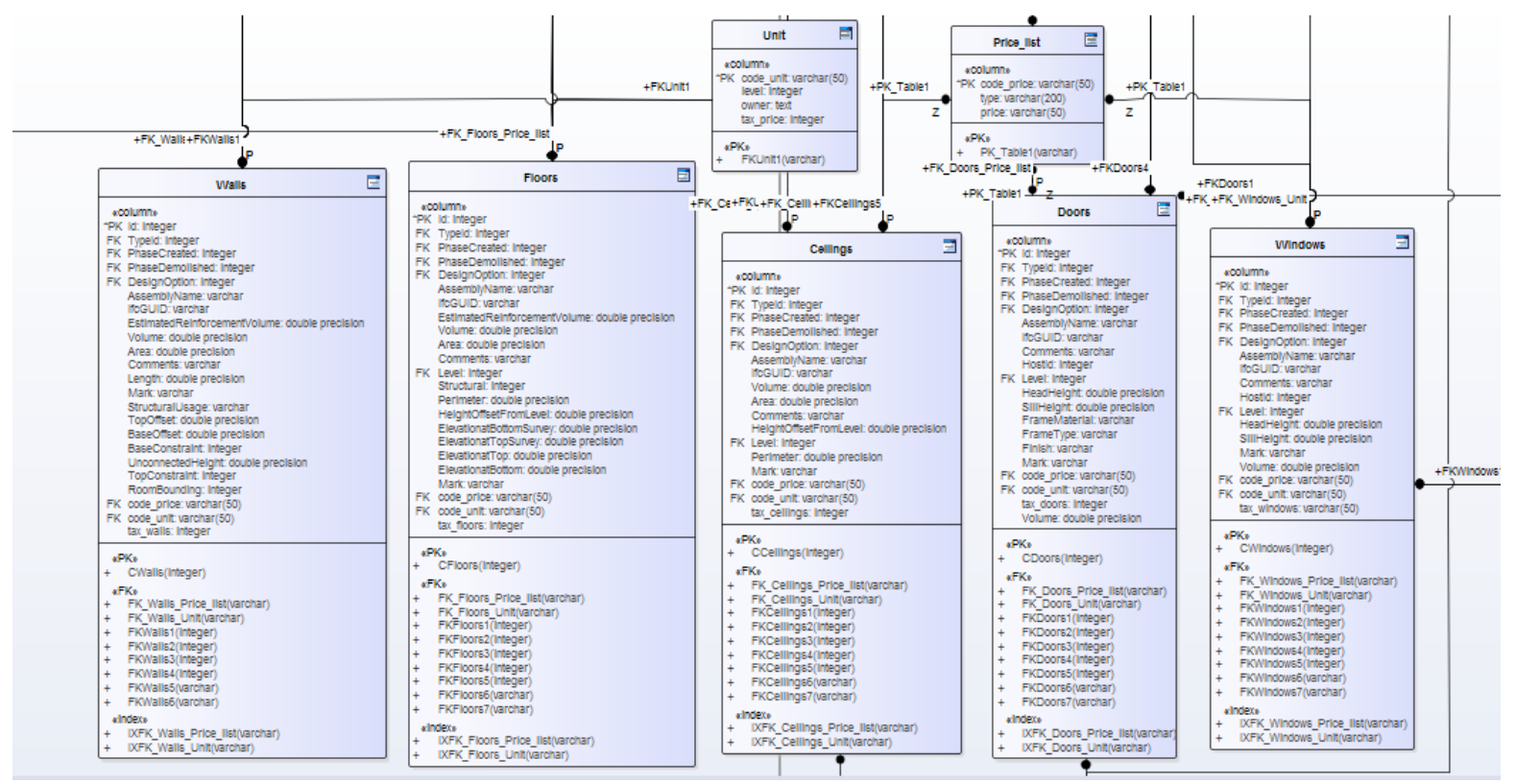

Figure 9. The modification of database structure

\begin{tabular}{|l|l|l|l|}
\hline & $\begin{array}{l}\text { code_price } \\
\text { [PK] character varying(20) }\end{array}$ & $\begin{array}{l}\text { type } \\
\text { character varying(200) }\end{array}$ & $\begin{array}{l}\text { price } \\
\text { integer }\end{array}$ \\
\hline $\mathbf{1}$ & C01 & Metal Ceiling & 184214 \\
\hline $\mathbf{2}$ & D01 & Wood Door & 1117904 \\
\hline $\mathbf{3}$ & D02 & Alumunium Door & 1151952 \\
\hline $\mathbf{4}$ & F01 & Porcelain Floor & 1361482 \\
\hline $\mathbf{5}$ & WD01 & Wood, Glass, Window & 722170 \\
\hline $\mathbf{6}$ & WD02 & Alluminum, Glass, Window & 711869 \\
\hline $\mathbf{7}$ & WL01 & Brick Walls & 454942 \\
\hline$*$ & & & \\
\hline
\end{tabular}

Figure 10. The contents of price list entity 


\begin{tabular}{l|l|l|l|l|l|l|l}
\hline & $\begin{array}{l}\text { Code_unit } \\
\text { [PK] character varying(20) }\end{array}$ & $\begin{array}{l}\text { level } \\
\text { integer }\end{array}$ & $\begin{array}{l}\text { owner } \\
\text { character(50) }\end{array}$ & $\begin{array}{l}\text { tax_price } \\
\text { integer }\end{array}$ \\
\hline 1 & L1U1 & 2 & Andri & 5672020 \\
\hline$*$ & & & &
\end{tabular}

Figure 11 . The contents of unit entity

On Price list entity, 'code_price' attribute is a unique code connecting entities, 'type' attribute is the material type of every object tax, and 'price' attribute is the calculation of the object type per $\mathrm{m}^{3}$. Whereas on the Unit entity, 'code_unit' attribute is a unique code to simplify the connection between entities, 'level' attribute is floor level of the unit location in the building, 'owner' attribute is the name of the unit owner, and 'tax_price' attribute is the unit tax calculation.

Figure 9, 10, and 11 described how to build the database structure to manage the building tax on $3 \mathrm{D}$ form, but adding non-spatial information is done manually. The unit tax calculation needs the SQL language. So that, the entities on Figure 9, 10, 11 is filled automatically by running the SQL language program.

\section{Discussion}

The typical approach to assess the building models is the normal distance between the point cloud and the object position that is considered true (Doringner and Pfeifer, 2008; Akca et al., 2010; Oude Elberink and Vosselman, 2011) but in this research, the assessment quality of geometric object was based on the volume not the comparability between point clouds data and the real objects. The result of geometric object RMSE is $0.001 \mathrm{~m}$. Meanwhile the unit tax calculation using $\mathrm{RCN}$ is based on volume object per meter. It means that the $3 \mathrm{D}$ modelling processed using BIM concept is very suitable for apartment unit tax calculation. As mentioned by Oosterom (2018), BIM designed object has a scale of $1: 1$. It may fit to reality but maybe not to the cadastral map.

Open Geospatial Consortium (OGC) defines LODs (Levels of Detail) of geometric object modelling into five levels. LODs are required to give the consideration in acquisition process, and represent the visual and data analyses. There are five definition of LODs; LOD0 is represent as 2D boundary with height representation; LOD1 is the development of LOD0 with flat roofs; LOD2 is the development of LOD1 but the model of roof structures is more advance and may also represent the vegetation objects; LOD3 is the development of LOD2 with advanced detailed in resolution textures of walls, roofs, structures, balconies, bay and projections; LOD4 is the development of LOD3 with interior structures inside the buildings (Biljecki et al., 2013). Data acquisition methods and modelling using BIM concept in this research provide LOD4 that gives the $3 \mathrm{D}$ modelling up to interior object inside the apartment units. The requirement taxation objects on Table 3 can produce $3 \mathrm{D}$ modelling that are integrated to the object's information. Figure 9 shows the database modification from BIM database concept to calculate the apartment unit calculation. It means that BIM database structure could be modified into the user needs.

As mentioned before in sub-chapter 2.1.1, fiscal cadastre requires the description, the boundaries definition, ownership, and the land value (Maurer \& Paugam, 2000). BIM system can fulfill the fiscal cadastre requirement by providing information and visualization of boundaries, ownership, and apartment units in 3D form.

\section{Conclusion}

BIM can be used to support the 3D fiscal cadastre, because:

a) The accuracy of geometric object using TLS is below the smallest unit $(\mathrm{m})$ of the unit tax calculation. The result of geometric object RMSE is $0.001 \mathrm{~m}$. The geometric of taxation object model represent the object in reality.

b) The requirement taxation objects can produce $3 \mathrm{D}$ modelling that are integrated to the object's information. It is included in LOD4 specification.

c) The BIM database structure can be modified to calculate the requirement to calculate the apartment unit calculation using RCN methods.

However, this study needs further research regarding the most suitable database structure for $3 \mathrm{D}$ fiscal cadastre and build 3D fiscal cadastre application from BIM system because based on this research, BIM database structure only provides the physical geometric object and its information, and must be modified to include the other entities of apartment unit tax calculation.

\section{Acknowledgement}

This research was partially supported by PT. Asaba who provided the TLS instrument for data acquisition, and P3MI-ITB who provided the funding for this research

\section{References}

Akca, D., Freeman, M., Sargent, I., \& Gruen, A. (2010). Quality Assessment of 3D Building Data. The Photogrametric Record 25 (132), 339 - 355.

Barus, B. R., Prasetyo, Y., \& Hani’ah. (2017). Analisis Akurasi Pemodelan 3D Menggunakan Metode Close Range Photogrammetry (CRP), Unmanned Aerial Vehicle 
(UAV) dan Terrestrial Laser Scanner (TLS). Jurnal Geodesi Undip.

Biljecki, F., Zhao, J., Stoter, J., \& Ledoux, H. (2013). Revisiting The Concept of Level of Detail in 3D City Modelling. ISPRS Annals of The Photogrammetry, Remote Sensing and Spatial Information Sciences (pp. 63-74). Istanbul: ISPRS.

Bird, R. M., \& Slack, E. (2002). Land and Property Taxation: A Review. Retrieved from http://wwwl.worldbank. org/publicsector/decentralization/June2003Seminar/ LandPropertyTaxation.pdf

Demchak, G., Krygiel, E., \& Dzambazova, T. (2009). Introducing Revit Architecture 2010: BIM for Beginners. New Indiana: Wiley Publishing, Inc.

Elberink, S. O., \& Vosselman, G. (2009). Building Reconstruction by Target Based Graph Matching on Incomplete Laser Data: Analysis and Limitations. Sensors 9 (8), 6101 - 6118.

EUBIM. (2017). Handbook for The Introduction of Building Information Modeling by The European Public Sector.

Kerosuo, H., Miettinen, R., Paavola, S., Maki, T., \& Korpela, J. (2015). Challenges of the expansive1 use of Building Information Modeling (BIM) in construction projects. journal of ABEPRO.

Kreider, R., \& Messner, J. (2013). The Uses of BIM: Classifying and Selecting BIM Uses. Pennsylvania: The Pennsylvania State University, University Park.

Laing, R., Leon, M., Mahdjoubi, L., \& Scott, J. (2014). Integrating Rapid 3D Data Collection Techniques to Support BIM Design Decision Making. International Conference on Design and Decision Support System in Architecture and Urban Planning (pp. 120-130). Elsevier.

Maurer, R., \& Paugam, A. (2000). Reform toward Ad Valorem Property Tax in Transition Economics: Fiscal and Land Use Benefits. The World Bank. Retrieved from http:// www1.worldbank.org/publicsector/decentralization/ June2003Seminar/paugnam.pdf

Mordue, S., Swaddle, P., \& Philip, D. (2016). Building Information Modeling for Dummies. Great Britain: John Willey \& Sons, Ltd.
National Institute of Building Science (NIBS). (2015). National BIM Standard-United States (Version 3). NIBS. Retrieved from https://www.nationalbimstandard.org/ files/NBIMS-US_FactSheet_2015.pdf

Oosterom, P. V., Lemmen, C., Thompson, R., Janecka, K., Zlatanova, S., \& Kalantari, M. (2018). 3D Cadastral Information Modelling. International Federation of Surveyors (FIG) (pp. 95-131). Turkey: International Federation of Surveyors (FIG).

Quentiro, M., Genechten, B., Bruyne, M., Poelman, R., Hankar, M., Barnes, S., \& Taronger, J. (2008). Theory and Practice on Terrestrial Laser Scanning: Training Material Based on Practical Applications (4 ed.). Valencia, Spain: Universidad Politecnica de Valencia Editorial.

Reshetyuk, Y. (2009). Self-Calibration and Direct Georeferencing in Terrestrial Laser Scanning (Doctoral dissertation). Stockholm, Sweden: Royal Institute of Technology (KTH).

Setiawan, A. (2016). Pemetaan Topografi Menggunakan Teknologi Laser Scanner (Studi Kasus: Daerah Kiara Payung Sumedang) (Bachelor's thesis). Bandung, Indonesia: Institut Teknologi Bandung.

Shaikh, A. A., Raju, R., Malim, N. L., \& Jayaraj, G. K. (2016). Global Status of Building Information Modeling (BIM) - A Review. International Journal on Recent and Innovation Trends in COmputing and Communication, 4(3), 300-303.

Stoter, J. E. (2004). 3D Cadastre (Doctoral dissertation). Delft, Netherlands: Faculty of Geo-Information Science and Earth Observation, University of Twente.

Syahfitriane, T. (2018). Pembangunan Basis Data Spasial untuk Penentuan Pajak Bumi dan Bangunan Unit Hunian Apartemen di Kota Bandung (Studi Kasus: Apartemen Parahyangan Residence) (Bachelor's thesis). Bandung, Indonesia: Institut Teknologi Bandung.

Williamson, I.P. (2013). Cadastres and Land Information Systems in Common Law Jurisdictions. Survey Review Journal, 114-129. 